De Arte, 9, 2010, pp. 61-70

ISSN: 1696-0319

\title{
El Toledo que conoció Hieronymus Münzer
}

\author{
Verónica GIJÓN JIMÉNEZ \\ Universidad de Castilla-La Mancha
}

RESUMEN. El viajero Hieronymus Münzer recorrió España en los años 1494 y 1495. Dejó por escrito las experiencias de su viaje en su obra Itinerarium sive peregrinatio per Hispaniam, Franciam et Alemaniam. Münzer llegó a España en un momento clave desde el punto de vista histórico y artístico. El último reino musulmán había sido reconquistado, se acababa de descubrir el Nuevo Mundo. En el plano artístico había una gran actividad, estaban siendo levantados muchos nuevos edificios, algunos de ellos bajo el mecenazgo de los Reyes Católicos. Toledo era una de las ciudades más importantes en esta época, escenario de todos los cambios que se estaban produciendo. A través del relato de Münzer estudiaremos el panorama artístico toledano.

Palabras clave: Historia del Arte, Literatura de Viajes, Toledo, Hieronymus Münzer.

Résumé. Le voyageur Hieronymus Münzer a parcouru l'Espagne dans les années 1494 et 1495. Il a laissé par écrit les expériences de son voyage dans son ouvrage Itinerarium sive peregrinatio per Hispaniam, Franciam et Alemaniam. Münzer est arrivé en Espagne à un moment-clef du point de vue historique et artistique. Le dernier royaume musulman avait été reconquis, le Nouvel Monde avait été découvert. Sur le plan artistique, il y avait une grande activité, on était en train d'élever beaucoup de nouveaux bâtiments, sous le mécénat des Rois Catholiques. Tolède était une des villes le plus importantes dans cette époque, théâtre de tous les changements qui étaient en train de se produire. Par l'intermédiaire du récit de Münzer, nous étudierons le panorama artistique de Tolède.

Mots clé: Histoire de l'Art, Littérature de voyages, Tolède, Hieronymus Münzer.

Los relatos de viaje constituyen una prolífica fuente para el estudio de la Historia del Arte. Los viajeros eran pioneros y en muchos casos sus relatos eran la única fuente de información para sus compatriotas sobre tierras lejanas. Por ello trataban de conocer con minuciosidad todo aquello que consideraban digno de interés. En muchos de estos relatos se recogieron descripciones de obras de arte, que hoy en día nos aportan una valiosa información. Uno de los relatos de viajes más importantes para nuestro país es el de Hieronymus Münzer.
Itinerarium sive peregrinatio per Hispaniam, Franciam et Alemaniam. ${ }^{1}$

\footnotetext{
${ }^{1}$ Hieronymus Münzer nació en Feldkirch (Vozelberg), en el límite occidental de la región del Tirol en 1460 en el seno de una familia adinerada. Obtuvo el grado de doctor en medicina en la Universidad de Pavía en 1479. Ejerció su profesión en Nuremberg y en 1484 viajó a Italia huyendo de un brote de peste pero pronto regresó a esta ciudad. Entre 1494 y 1495 realizó su viaje a España. Murió en 1508. R. ALBA, "nota introductoria", en J. MÜNZER, Viaje por España y Portugal, Madrid 2002.pp. X-XII. J. GARCíA MERCADAL, «Jerónimo Münzer», en Viajes de extranjeros por España y Portugal, vol. I, Salamanca, 1999, p.305.
} 
Se cree que Münzer vino a España huyendo de una epidemia de peste, pero hay muchos motivos para pensar que la verdadera razón de su viaje, era cumplir una misión secreta para el emperador Maximiliano I. Debía verificar los rumores que habían llegado a su país sobre el descubrimiento de America y averiguar los planes que los reyes españoles tenían al respecto. ${ }^{2}$ Viajaba acompañado por tres amigos hijos de comerciantes ricos; Antonio Herwart, Gaspar Fischer y Nicolás Wolsentein. Algunos de ellos hablaban italiano y francés, aunque Münzer no tuvo problemas para comunicarse en latín.

Los viajeros recorrieron la península durante cinco meses, pasaron la frontera por La Junquera el 19 de septiembre de 1494, visitando después algunos lugares de Cataluña como Figueras, Gerona y Montserrat. El 4 de octubre llegaron a Villarreal y después pasaron por Valencia, Alcira, Játiva, Alicante, Elche, Orihuela y Murcia. Desde aquí se dirigieron a Granada, pasando primero por lugares como Almería, donde visitó la mezquita, o Guadix. En Granada permaneció tres días y visitó La Alhambra guiado por su alcaide, Iñigo López, conde de Tendilla. La descripción de Granada es la más extensa de su relato y constituye un documento de gran importancia puesto que es una de las primeras después de la reconquista de la ciudad. ${ }^{3} \mathrm{El}$ 5 de noviembre llegó a Sevilla, donde permaneció hasta el día 10 y allí vio la catedral en construcción y parte de la mezquita mu-

\footnotetext{
${ }^{2}$ Con este viaje Münzer buscaba la colaboración del rey de Portugal para encontrar las costas de Asia navegando hacia occidente. Antes de su viaje había sido editor de obras geográficas y había colaborado con Martín Behaim en la confección de un globo terráqueo. El 14 de Julio de 1493 Münzer escribió una carta al rey de Portugal en la que trataba de este asunto: "Considerando estas cosas, Maximiliano, invictísimo rey de Romanos, quiere invitar a tu majestad a buscar la tierra oriental de Catay..." Ibídem. p. 174

${ }^{3}$ Ibídem. pp. 89-139
}

sulmana que aún persistía. Dos días después pasó a Portugal, visitando ciudades como Évora, Lisboa, Coimbra y Oporto; en la primera ciudad se entrevistó con el rey de Portugal Juan II. $^{4}$ Desde allí pasaron a Galicia, deteniéndose seis días en Santiago de Compostela y después atravesó Castilla y León hasta llegar al monasterio de Guadalupe. El 14 de enero de 1495 llegó a Toledo, desde donde se dirigió a Madrid para entrevistarse con los Reyes Católicos. Finalmente fue a Guadalajara y a Zaragoza para salir del país por Roncesvalles el 9 de febrero, no sin antes visitar Pamplona. ${ }^{5}$

Como vemos el recorrido que hizo Münzer por nuestro país fue muy completo y tuvo lugar en una etapa clave de nuestra historia. Justo en la frontera entre la Edad Media y la Edad Moderna, un momento de profundos cambios para España, que se estaba convirtiendo en la potencia que sería años más tarde. ${ }^{6}$

Aunque Münzer pasó por numerosas ciudades y pueblos durante su viaje, no permaneció en muchas de ellas más de un día. En Toledo estuvo durante tres días y el mismo la consideró como una de las ciudades más importantes del reino, Junto con Barcelona, Valencia, Granada, Sevilla, Zaragoza y Madrid. También es una de las ciudades más representativas de esta época, sede de la iglesia Primada de España, favorecida por los monarcas y con una gran

\footnotetext{
${ }^{4}$ Ibídem. pp. 153-167

${ }^{5}$ R. AlVA, op. cit., pp. XXII- XXIII.

${ }^{6}$ El mismo Münzer pone esto de manifiesto en el discurso que hizo en Madrid ante los Reyes Católicos el 24 de enero de 1495. Los reyes habían pacificado el país y habían reconquistado las últimas tierras que quedaban en manos de los musulmanes, de manera que se creaba una situación propicia para la construcción de un estado moderno con un prometedor futuro, gracias al reciente descubrimiento de América, que auguraba una pronta expansión territorial y la llegada de abundantes riquezas. J. MÜNZER, op .cit., pp. 265271 y J. FISCHER El doctor Jerónimo Münzer (Monetario) Su viaje por España (1495-1496), Madrid, 1923.
} 
actividad artística ligada tanto al poder eclesiástico como al poder civil.

\section{LA LLEGADA DE MÜNZER A TO- LEDO Y SUS PRIMERAS IMPRE- SIONES}

Las primeras palabras que Münzer dedicó a Toledo, fueron para dar una imagen de su apariencia desde el exterior, hizo una descripción de su panorámica que posteriormente sería repetida por los demás viajeros que visitaron la ciudad y que se tradujo en las imágenes de la época que conservamos: ${ }^{7}$

"Toledo es una de las más preclaras ciudades de Hispania. Está situada en un monte y muy fortificada. La rodea en sus tres cuartas partes el Tajo, por un profundo valle. Su situación, por así decirlo es como la de Berna, en Suiza, aunque el monte y la subida, por todas partes, es más empinada.

¡Oh, que murallas más firmes tiene, levantadas por los sarracenos, y qué fortificada está por la naturaleza y el arte!". 8

Como vemos la descripción de Toledo hecha por Münzer es muy ilustrativa y en ella incluye las murallas. Compara su situación con la de la cuidad de Berna. Veremos que un poco más adelante la compara con Nuremberg, para dar una idea de su tamaño y su población. Todas las ciudades españolas que visitó Münzer son comparadas con otras ciudades europeas, preferentemente alemanas, que son tomadas por el autor como referencia para dar a conocer a sus compatriotas su tamaño y su apariencia.

Durante su estancia en Toledo Münzer presenció el traslado del cuerpo del

\footnotetext{
${ }^{7}$ D. Peris SÁnchez y E. Almarcha Núñez HeRRADOR La ciudad y su imagen, Toledo, 2009, p.25

${ }^{8}$ J. MÜNZER, op. cit., p. 247.
}

Cardenal Mendoza desde Guadalajara hasta Toledo, según sus propias palabras "con tanto esplendor pompa y solemnidad, como no puede haber más." ${ }^{9}$ Otros textos de la época recogieron este traslado, y nos pueden dar una idea de lo que presencio Münzer: El cardenal había muerto en Guadalajara el 11 de enero y el cortejo fúnebre salió hacia Toledo al día siguiente. En el iban familiares del difunto, como don Pedro Hurtado de Mendoza o los condes de Tendilla, religiosos de todas las ordenes, personalidades eclesiásticas y caballeros de Guadalajara. Según el autor del texto serían más de tres mil personas.

Llegaron a Toledo el 16 de enero. Allí salieron a recibirlo el cabildo catedralicio, representantes de todas las parroquias de la ciudad y los religiosos de todos los monasterios. Antes de entrar por la puerta de Bisagra, cerca de la ermita de San Lázaro había un primer túmulo adornado con numerosas hachas encendidas. En dicho túmulo se depositó el cuerpo vestido de pontifical como arzobispo de Toledo y se le cantaron responsos. Después fue llevado a la catedral en una procesión en la que además de religiosos iban miembros del ayuntamiento, regidores, jurados y caballeros de la ciudad. En la catedral había otros dos túmulos, uno grande y otro pequeño y allí el sábado 17 de enero se dijo la misa mayor del entierro. ${ }^{10}$ Münzer no la pudo presenciar, puesto que se marchó de Toledo ese mismo día.

\section{VISITA A LA CATEDRAL DE TO- LEDO}

El primer monumento al que hace re-

\footnotetext{
${ }^{9}$ Ibídem, p, 147.

${ }^{10}$ P. SALAZAR MENDOZA, «Entierro y honras fúnebres del cardenal don pedro González de Mendoza. Crónica del gran Cardenal de España», en F. LAYNA SERRANO, Historia de Guadalajara y sus Mendoza en los siglos XV y XVI, vol. II, Guadalajara, 1994, pp. 482 483.
} 
ferencia Münzer, es la Catedral, cuyas bóvedas habían sido cerradas justo en ese siglo. ${ }^{11}$ Resalta su belleza, pero aún más su riqueza y su importancia, por ser la Catedral Primada de España. No se detiene mucho a describirla, ya que sólo menciona sus medidas y a la distribución de sus naves y sus capillas, que le parecen bien decoradas y alude a los sepulcros de los reyes, que se encuentran en ellas:

"No hemos visto en España, ya terminada, catedral semejante en belleza $y$ hermosura. Su longitud es de doscientos veinte pasos, y su anchura de cuarenta y siete. [...] Tiene dos naves a cada lado, y detrás del coro, tres, de las cuales la última, por la cabeza, está más baja, para capillas, que son soberbias, amplias y muy bien decoradas. En ellas están los sepulcros de los reyes." 12

Como ya he apuntado las bóvedas se habían cerrado en 1493, de manera que Münzer ve el edificio terminado en lo fundamental, aunque la Catedral seguirá siendo el núcleo artístico más importante de Toledo durante varios siglos, ya que a partir de este momento se siguieron construyendo portadas, capillas y se dota a la catedral de mobiliario, como rejas, retablos y sillerías. ${ }^{13}$ Para Münzer, la Catedral toledana es la más bella de las construidas en España, sin embargo el autor no remarca la peculiar influencia del arte islámico que se puede apreciar en ella, como la carencia de la armonía en las proporciones, que si se encontraba en las catedrales góticas francesas, su tendencia a la horizontalidad y los

${ }^{11}$ R. DíAz Del Corral GARNicA, Arquitectura y Mecenazgo. La imagen de Toledo en el Renacimiento, Madrid, 1987. p. 263

${ }^{12}$ J. MÜNZER, op. cit., p. 247-249

${ }^{13}$ P. NAVASCUÉS, La Catedral Primada de Toledo, Madrid, 2002, pp. 23,24. Ver también: I. DE LAS CASAS El conocimiento de la arquitectura en la Catedral de Toledo, Madrid, 1992.R. GonZÁlveZ, La Catedral de Toledo, 1549: según el Dr. Blas Ortiz, Toledo, 1999. vanos polilobulados del crucero. Tampoco nota la originalidad del tema tallado en la sillería baja, sobre la que sí reparó, que había sido realizada por un artista de la baja Alemania, que era Rodrigo Alemán y que cuando Münzer visitó la catedral debía estar terminada o a punto de estarlo:

"Los asientos del coro son muchos y fueron tallados de nuevo por cierto escultor de la baja Alemania. En cada uno de los sitiales está bellamente esculpida una escena de la conquista de la ciudad y castillo de Granada, de manera que puedes contemplar la guerra granatense como si la tuvieras ante los ojos."14

Los relieves aun seguían una estética gótica, pero el tema desarrollado es de gusto renacentista, puesto que glorificaba una campaña militar que tuvo lugar en el momento de realización de la obra. El fin de la utilización de este tema era la de la exaltación de la figura de los reyes, y sobre todo la del cardenal Mendoza que aparece estrechamente ligado a ellos, no en vano era considerado el tercer rey de España. En la elección del tema vemos una conciencia clara del valor conmemorativo de la imagen, propia del renacimiento. ${ }^{15}$

La parte de la Catedral sobre la que más hablaban la mayoría de los viajeros es el tesoro, que normalmente era mostrado a los visitantes sin reparos. En esta época el rasgo más apreciado en las obras de arte era la suntuosidad en su construcción y la riqueza de los materiales, y por eso el tesoro de la catedral de Toledo asombraba a los viajeros y era muy valorado. ${ }^{16}$ Después

\footnotetext{
${ }^{14}$ J. MÜNZER, op. cit., p. 249

${ }^{15}$ J. CAMÓN AZNAR, «La arquitectura y la orfebrería española del siglo XVI», en Summa Artis, vol. XVII, Madrid, 1963, p. 29 y 30. Sobre el coro de la catedral de Toledo ver I. RíO DE LA HOZ, El coro de la Catedral de Toledo, Madrid, 1992.

${ }^{16}$ En esta época, la riqueza de los materiales de las obras de arte eran el rasgo más apreciado, incluso por
} 
enumera sus principales piezas como los cálices, las cruces, los báculos la Biblia de San Luís y las ropas litúrgicas de ricos tejidos. También hace una especial mención a los relicarios y su contenido, dada la importancia del culto a las reliquias en esta época, puesto que aún no se había realizado la reforma luterana. Entre las más notables encontramos un trozo de lignun crucis. En esta época el tesoro se guardaba en la antigua sacristía, que a mediados del siglo XVI fue destruida para construir la actual. El autor no hace una descripción detallada, pero menciona su decoración pictórica en la que se podían ver las virtudes, y la compara con la Capilla Sixtina:

"Vimos primeramente el amplio sagrario, decorado con tan bellas pinturas, que te creerías estabas viendo la capilla de Sixto IV en Roma.

Me enseñaron primeramente más de cien imágenes cálices, cruces y otros vasos, bustos, todo de oro y de plata, llenos de reliquias." 17

\section{SAN JUAN DE LOS REYES Y LOS CONVENTOS DE TOLEDO}

El segundo edificio en el que Münzer centra su atención, es el monasterio de San Juan de los Reyes, cuya iglesia, estaba terminada menos el coro. ${ }^{18}$

encima del estilo. Esto hace que casi todos los viajeros describan en sus relatos los tesoros de las catedrales, Münzer no es una excepción. P. SHAW FAIRMAN, España vista por los ingleses del siglo XVII, Madrid, 1981.

${ }^{17}$ J. MÜNZER, op. cit., p. 249.

${ }^{18}$ No se conoce la fecha exacta del comienzo de las obras de San Juan de los Reyes, sólo contamos con el dato de que en 1486 ya vivían algunos monjes en el edificio, pero es la descripción de Jerónimo Münzer la que realmente nos permite conocer el estado de las obras, de ahí que se suela utilizar como fuente para el estudio de esta iglesia. Ver. R. DEL CERRO MALAGÓN, y otros, Arquitectura de Toledo. Del Románico al Gótico, vol. I, Toledo, 1992, p. 492.B. MARTÍNEZ CAVIRÓ, El monasterio de San Juan de los Reyes: Toledo, 2002, p. 26. Sobre San Juan de los Reyes ver también: J. YARZA LUACES,
"Los reyes don Fernando y doña Isabel han mandado construir este monasterio, que es de piedra de sillería, con verdadera magnificencia. En la iglesia (que excepto el coro, está ya terminada) se ven los escudos empresas de los monarcas, la efigie de su patrono San Juan Bautista y otras imágenes de santos. De los muros exteriores del templo penden cadenas y grillos de los cautivos cristianos de Granada, puestos allí en memoria suya y en la de sus libertadores, y son tantos, que no bastarían dos carros para llevarlos. Me dijo el arquitecto de la obra que ésta vendrá a costar unos doscientos mil ducados.

Los frailes de la Orden de San Francisco; guardan la regla con estrecha rigidez y hacen vida ejemplar." 19

Éste fue uno de los edificios más importantes de los que se construyeron en esta época, pues su cometido era conmemorar la victoria en la batalla de Toro, que había otorgado a Isabel la corona de Castilla, y también el nacimiento del infante Juan, cuyo patrón daba nombre a la iglesia. Además el templo estaba dedicado a la exaltación de los monarcas, ya que estaba previsto que fuera panteón real antes que la reconquista de Granada, hiciera cambiar de planes a los reyes.

El templo se comenzó con trazas de Juan Guas en 1477, al que quizás Münzer conoció, ya que él dice haber hablado con el arquitecto sobre los costes de la obra, 200.000 ducados. El edificio está dedicado a la gloria de los reyes, como nos dejan ver los escudos que tapizan sus paredes, protegidos por el águila de San Juan Evangelista. El estilo que se eligió para su construcción fue el gótico borgoñón que habían traído algunos arquitectos llegados a España hacia

Isabel la Católica. Promotora Artística, León, 2005, pp. $15-24$.

${ }^{19}$ J. MÜNZER, op. cit. pp. 253-255 
la mitad de siglo. Juan Guas pertenecía a la segunda generación y había sido capaz de sintetizar este gótico tardío prolijo en decoración naturalista y la tradición musulmana que había cristalizado en el mudéjar.

La iglesia era de nave única con capillas laterales entre contrafuertes, y con transepto hipertrofiado que se percibe en planta por que su tramo es más ancho que los demás, y en alzado porque es más alto que las naves. Es en la decoración descrita por Münzer, en la que encontramos la huella de lo islámico. Los escudos de armas de los reyes, que tapizan las paredes repitiéndose una y otra vez, como la decoración geométrica musulmana: los mocárabes, la decoración epigráfica que recorre el muro de nuevo alabando a los reyes y la cúpula que cubre el cimborrio, claramente influenciada por la mezquita de Córdoba. ${ }^{20} \mathrm{El}$ convento fue dado a los franciscanos de la observancia, a los que la reina Isabel favoreció notablemente, ${ }^{21}$ pues Münzer dice que en Toledo había seis monasterio bajo sus órdenes. ${ }^{22}$

Dentro de la política artística de los Reyes Católicos, ésta fue una de las obras más importantes y con más carga representativa en la cual, al igual que el cardenal Mendoza en la sillería baja del coro de la catedral, los reyes son conscientes del potencial del arte para afianzar la imagen del poder, y la imagen que los Reyes Católicos querían transmitir, era la de pacificadores

\footnotetext{
${ }^{20}$ D. PERIS SÁNCHEZ coord., op. cit., pp. 489-527

${ }^{21}$ La reina Isabel dio el convento a frailes franciscanos observantes, es decir, que seguían la Regla de la orden observante, aprobada en el concilio de Constanza de 1414 por el papa Juan XXIII, para que la orden retornara a la pureza primitiva que había ido perdiendo con el tiempo. Al dar el convento a los observantes la soberana pretendía suprimir la rama de los franciscanos claustrales, que aun seguían la regla antigua y vivían en un convento enclavado sobre lo que fue parte del palacio de Galiana. B. MARTíneZ CAVIRÓ, op. cit., pp. 12-13

J2. MÜNZER, op. cit., p. 259.
}

del reino y defensores de la religión. Este mensaje queda reforzado con las cadenas de los cautivos rescatados, que ya cuando la visitó Münzer colgaban en la fachada principal.

Después de hablar de San Juan de los Reyes, Münzer menciona otros conventos de la ciudad, pero no hace ninguna referencia a sus edificios, habla de ellos como institución. Del convento de la Santísima Trinidad, dice que era una antigua mezquita de los moros. Estaba ocupado por frailes de la Merced que pedían limosnas para rescatar cautivos de África. La información que nos da Münzer sobre este convento no son del todo ciertas, puesto que sabemos que era de Trinitarios calzados y que se fundó en 1220 en un pequeño hospital y unas casas cedidas por los caballeros de Pantoja en la calle Trinidad. En el siglo XVI experimentó un notable crecimiento que hizo necesario el derribo de los edificios existentes y la construcción de un nuevo claustro y una iglesia. Hoy en día este convento no existe, puesto que lo que quedaba de él se demolió en $19600^{23}$

El siguiente convento que menciona es el de San Agustín, lo localiza en un ángulo de la ciudad y asegura que fue una fortaleza de los sarracenos. En ese momento estaba ocupado por Frailes de la observancia. En este caso Münzer estuvo más acertado, puesto que en ese solar originalmente estuvo una fortaleza de los reyes godos, después fue alcázar musulmán y a continuación paso a manos de los reyes cristianos. A través de donaciones reales se convirtió en convento. Este estaba enclavado junto a la puerta del Cambrón, actualmente lo ocupa el centro educativo Sefarad, aunque la mayoría de sus edificaciones desaparecieron en el siglo XIX con la desamortiza-

\footnotetext{
${ }^{23}$ L. Moreno Demingue, F. Alguacil SAn Félix, Y P. AlguaCIl SAN FÉLIX, El Toledo invisible, Toledo, 2002, p. 152
} 
ción. Tras hablar de este edificio, menciona una leyenda que hace referencia a la toma de Toledo por los musulmanes, que habrían sido introducidos por los judíos en la ciudad. Esta leyenda se narra en la Primera Crónica General que posiblemente el autor oyó contar durante su viaje. El último convento que menciona es el de Santa Clara, que según el autor antes era un convento Benedictino. ${ }^{24}$ Esta afirmación seguramente es errónea, puesto que las monjas de Santa Clara se trasladaron al lugar que aún ocupan hoy en día, gracias a la donación de unas casas, hecha por María Meléndez en 1369. El autor remarca que en la ciudad hay más conventos, pero señala estos como los más importantes. ${ }^{25}$

Después de hablar sobre los monasterios, Münzer empezó a describir la cortesía del pueblo toledano y cómo las gentes admiraban mucho a su clero, pero dejó incompleto este apartado y no se conoce el motivo por él que no lo finalizó.

\section{A MODO DE CONCLUSIÓN}

La obra de Münzer constituye a una fiel pintura del panorama político, social y cultural de finales del siglo XV en nuestro país. Su relato nos introduce en una España de ciudades fuertemente amuralladas y grandes catedrales góticas en construcción, que aún no habían terminado de sustituir a las mezquitas. Es un escenario de apariencia fundamentalmente medieval, en el que se empiezan a experimentar tímidos y sutiles cambios que se concretaran ya en el siglo siguiente.

Es cierto que Toledo fue un importante núcleo renacentista, que constituyó una de las puertas de entrada del nuevo estilo en España, pero en la época en la que

\footnotetext{
24 J. MÜNZER, op. cit., pp. 257- 259

${ }^{25}$ B. MARTínez CABIRÓ, Conventos de Toledo, Madrid, 1990, p. 187.
}

Münzer visitó la ciudad no existía ningún monumento de este estilo. Al contrario los dos edificios en los que se centra la descripción del autor son la catedral, que había sido terminada hacía poco; y San Juan de los Reyes, que aun se estaba construyendo. Ambos edificios de estilo gótico, que era el que se utilizó en todas las construcciones religiosas que se llevaron a cabo en esta época bajo el mecenazgo de los Reyes Católicos. $^{26}$

Es interesante remarcar que a finales del siglo XV había otro estilo importante en Toledo, el cual no es mencionado en ningún momento por el autor, el mudéjar. Ya hemos visto como al describir la catedral de Toledo y San Juan de los Reyes no aprecia las influencias del arte hispanomusulmán, pero tampoco describe ningún edificio mudéjar. ${ }^{27}$ Quizá sea porque este viajero, a pesar de haber estado en Italia tenía una mentalidad centro europea y el estilo gótico le era más familiar y más similar a lo que se daba en su país.

En las descripciones de estos edificios y en el relato en general, Münzer no duda en alabar continuamente a los Reyes Católicos, sobre todo por lo mucho que estaban favoreciendo la religión católica en sus reinos, hecho que se traduce en la construcción de numerosos edificios religiosos y

\footnotetext{
${ }^{26}$ R. DÍEZ DEL CORRAL GARNICA, «Arquitectura y magnificencia en la España de los Reyes Católicos», en Reyes y Mecenas. Los Reyes Católicos, Maximiliano I y los inicios de la casa de Austria en España, Catalogo de exposición del 12 de marzo al 31 de mayo de 1992, Toledo, 1992 , p. 73

${ }^{27}$ No se puede esperar que un viajero se refiera al mudéjar por su nombre, puesto que José Amador de los Ríos acuñó este término en su discurso de ingreso a la Academia de Bellas Artes de San Fernando, que tuvo lugar el 19 de junio de 1859. Si sería posible que notara la influencia de arte árabe en estos edificios, pero el autor no se interesa por ellos. Sólo menciona el convento de Santa Clara y no lo describe ni hace ningún comentario sobre su posible filiación al arte islámico.
} 
la fundación de conventos, que el autor vio durante su viaje. No obstante el relato de Münzer es rico en detalles y a través de él se vislumbra una mentalidad mucho más abierta de lo que es normal para los relatos de esta época. Münzer se aproxima a lo desconocido con una actitud de humildad que le hace valorar lo diferente, e incluso lo contrario a sus creencias, como es el caso de los moriscos de Granada. Algunos estudiosos lamentan que en ocasiones el autor es demasiado parco en sus descripciones, ya que un hombre de su cultura podría habernos aportado mucha más información, teniendo en cuenta el momento estratégico en el que visitó nuestro país. No obstante, indudablemente este relato de viaje es una fuente muy valiosa para el estudio del arte español de esta época, ya sea desde el punto de vista político, social o artístico.

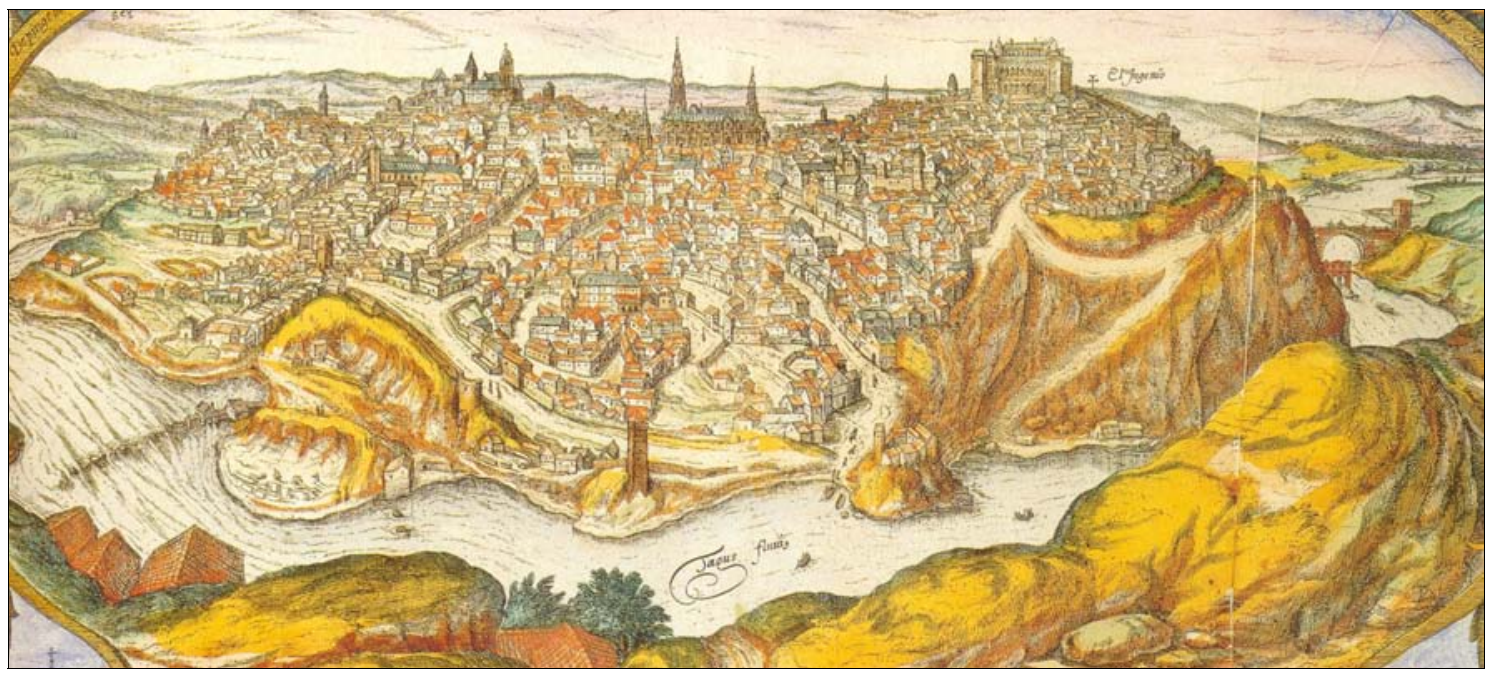

- Fig. 1. Detalle de la vista de Toledo, Hoefnagel, El Toledo Invisible, 1598. 


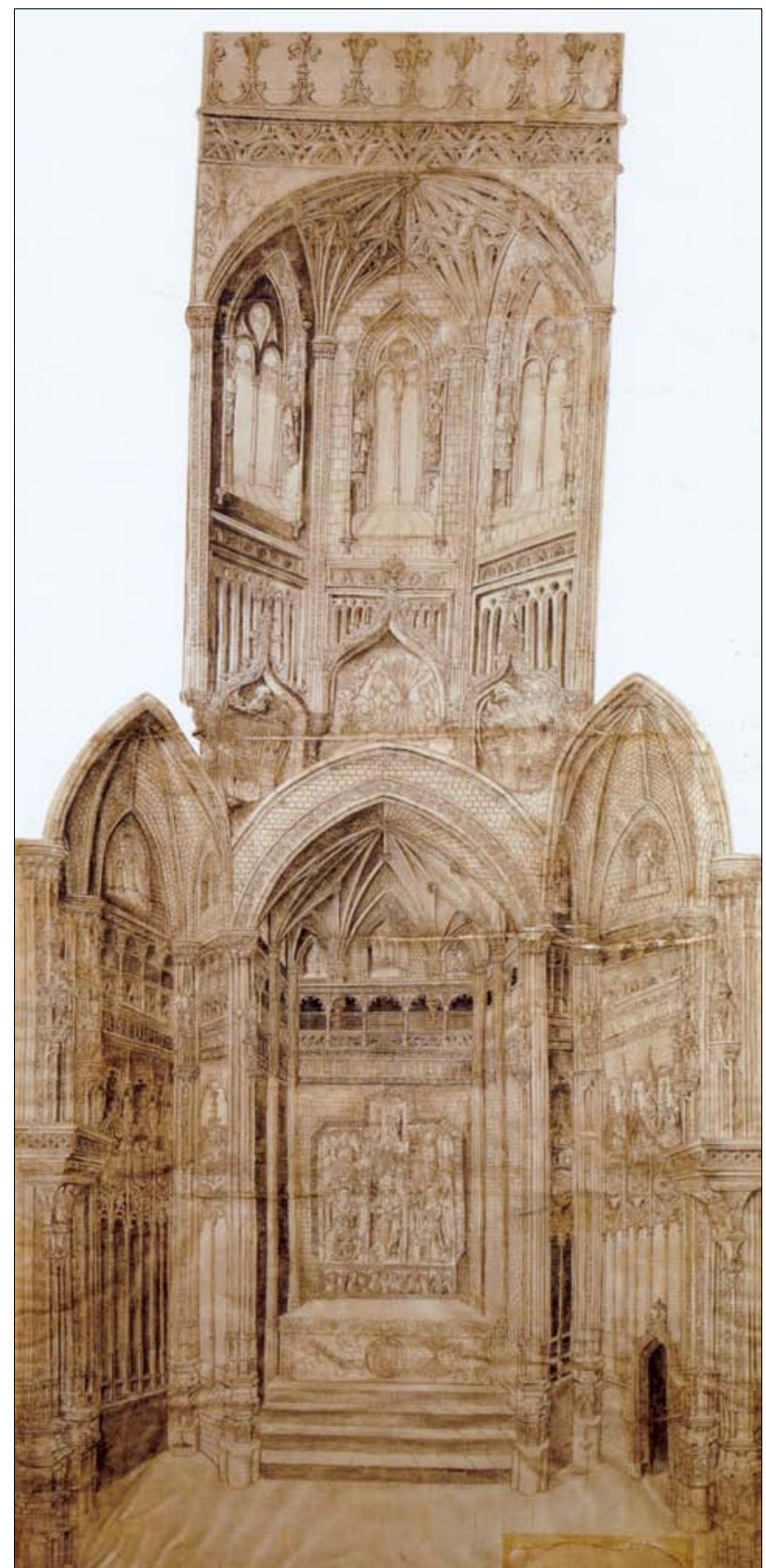

- Fig. 2. Diseño de la cabecera de San Juan de los Reyes, atribuida a Juan Guas, El Monasterio de San Juan de los Reyes de Toledo.. 


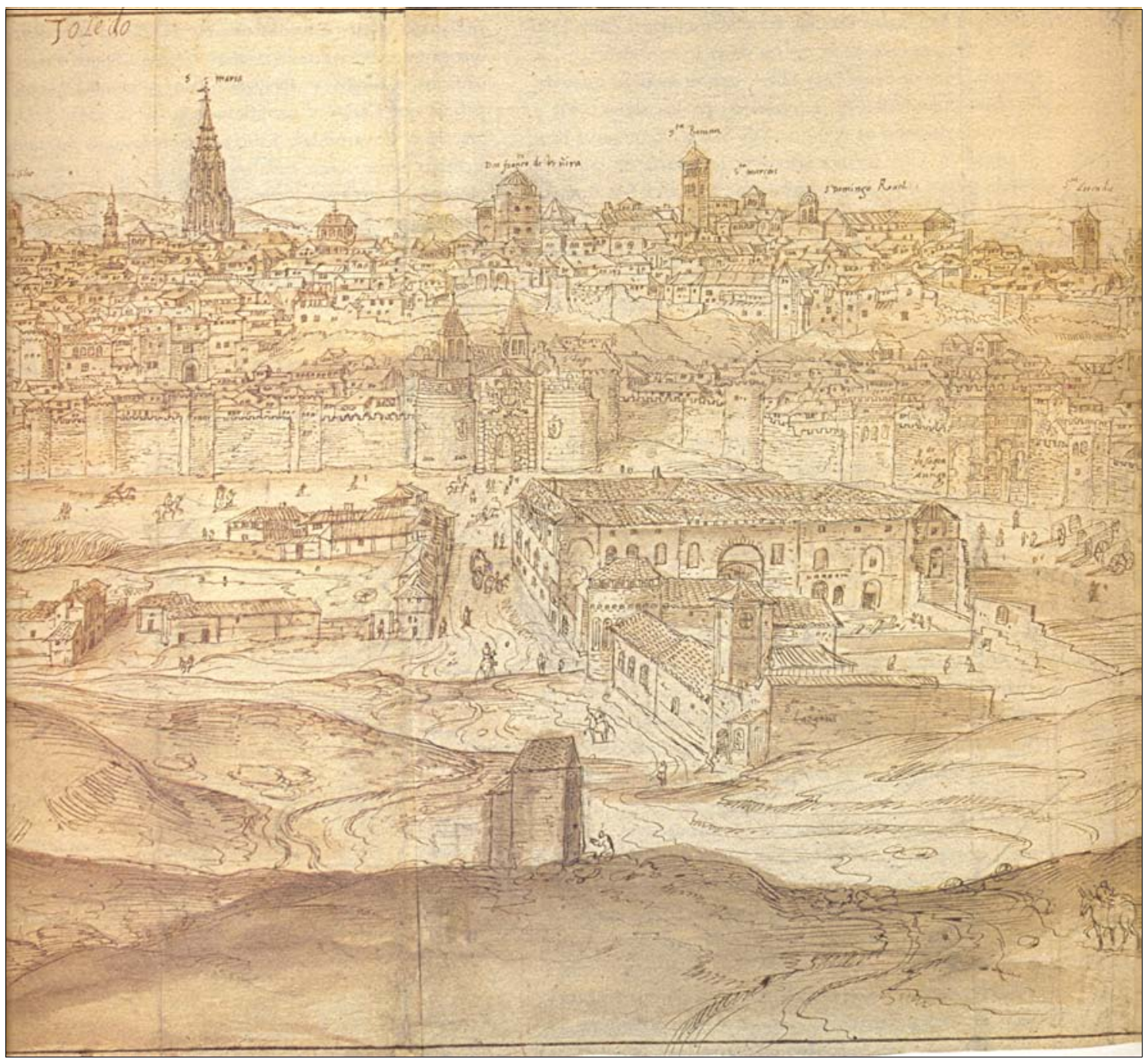

- Fig. 3. Detalle de la vista de Toledo, Anton Van den Wingaerde, Ciudades del Siglo de Oro. Las vistas españolas de Anton Van den Wingaerde, 1563. 